\title{
Brooke-Spiegler Syndrome With Cervical Spine Lesion
}

\author{
Valentina Vasenina $^{1}$, Thomas Cibull ${ }^{2}$, Noam Stadlan ${ }^{3,4}$ \\ 1. Neurosurgery, University of Chicago, Chicago, USA 2. Pathology and Laboratory Services, NorthShore University \\ HealthSystem, Evanston, USA 3. Neurosurgery, University of Chicago Pritzker School of Medicine, Chicago, USA 4. \\ Neurosurgery, NorthShore University HeathSystem, Chicago, USA
}

Corresponding author: Noam Stadlan, nstadlan@northshore.org

\begin{abstract}
Brooke-Spiegler syndrome (BSS) is a rare hereditary autosomal dominant disorder with variable phenotypic expressivity that results in a variety of benign cutaneous face, scalp, and neck tumors with a histology profile of cylindroma, spiradenoma and trichoepithelioma. Reports of lymph node and distant metastasis are scarce. We present the first case of Brooke-Spiegler syndrome with metastasis to the cervical spine. An 86year-old female with Brooke-Spiegler syndrome presented to the clinic with a finding of cervical spine lesion involving vertebral body, prevertebral, paraspinal, foraminal, and epidural spaces. The histopathology of the lesion showed benign cylindroma. Considering the location of the lesion and local invasion of neural structures, the malignant transformation of existing tumors could not be excluded. Brooke-Spiegler syndrome rarely presents with malignant transformation and distant metastatic spread. It is important to be aware of these rare cases while monitoring the disease and addressing clinical symptoms. This is to our knowledge the first case of metastatic spread of the cylindroma to the cervical spine resulting in local bone destruction and neural elements compromise. Physicians should be aware of this rare possibility.
\end{abstract}

Categories: Dermatology, Neurosurgery, Oncology

Keywords: carcinoma, hereditary skin neoplasms, sweat gland neoplasms, adenoid cystic, epidural space

\section{Introduction}

Brooke-Spiegler syndrome (BSS) is a rare autosomal dominant disorder with a variable phenotypic expression, which can present with multiple cutaneous adnexal neoplasms of the scalp, face, and neck with less frequent trunk and extremities involvement. Lesions begin to appear in late childhood-late adolescence and slowly increase in size and number. It is more prevalent in females [1-3]. Histologically, the defining lesions of Brooke-Spiegler syndrome are cylindromas, spiradenomas, and trichoepitheliomas. Multiple familial trichoepithelioma and familial cylindromatosis are phenotypic variants of Brooke-Spiegler syndrome. In addition to above-mentioned skin lesions, patients with Brooke-Spiegler syndrome may develop salivary gland tumors, basal cell carcinomas, trichoblastomas, milia, organoid nevi. Cylindromatosis gene (CYLD) tumor-suppressor gene mutation on chromosome 16 is detected in about $80-85 \%$ of patients with the classical Brooke-Spiegler presentation [4]. The terminology to refer to this condition and its

Received 07/25/2020

Review began 08/05/2020 Review ended 10/07/2020 Published 10/16/2020

\section{(c) Copyright 2020}

Vasenina et al. This is an open access article distributed under the terms of the Creative Commons Attribution License CC-BY 4.0., which permits unrestricted use, distribution, and reproduction in any medium, provided the original author and source are credited. phenotypic variants is changing and is now more commonly referred to as CYLD cutaneous syndrome (CCS) $[5]$.

Malignant transformation of cutaneous neoplasms occurs in 5-10\% of the patients [6]. Reports of lymph node and distant metastatic spread are extremely rare, though there are reports of pulmonary cylindroma [5]. We present the first case of Brooke-Spiegler syndrome with metastasis to the cervical spine.

\section{Case Presentation}

An 86-year-old female initially presented to our clinic with complaint of intermittent left arm pain and left fingers paresthesia in dermatomal distribution and left lower extremity pain for one year. The patient's medical history was significant for Brooke-Spiegler syndrome with multiple scalp lesions resected throughout her life and parotid basal cell adenoma. No changes to the scalp lesions were noted. The patient had no neurological deficits on physical exam.

CT of the cervical spine demonstrated lytic lesion of C7 vertebral body. MRI of the cervical spine showed 4.7 $\mathrm{x} 4.9 \mathrm{~cm}$ destructive heterogeneous soft tissue mass involving $\mathrm{C} 7$ vertebral body, pedicle and spinous process with extension into left C67, C7T1 neuroforamina, left C7 epidural space and left paravertebral/prevertebral space (Figure 1). The left C7 and C8 nerve root compression was consistent with patient's left arm radicular symptoms. The etiology of the left leg pain was unknown. 


\section{Cureus}
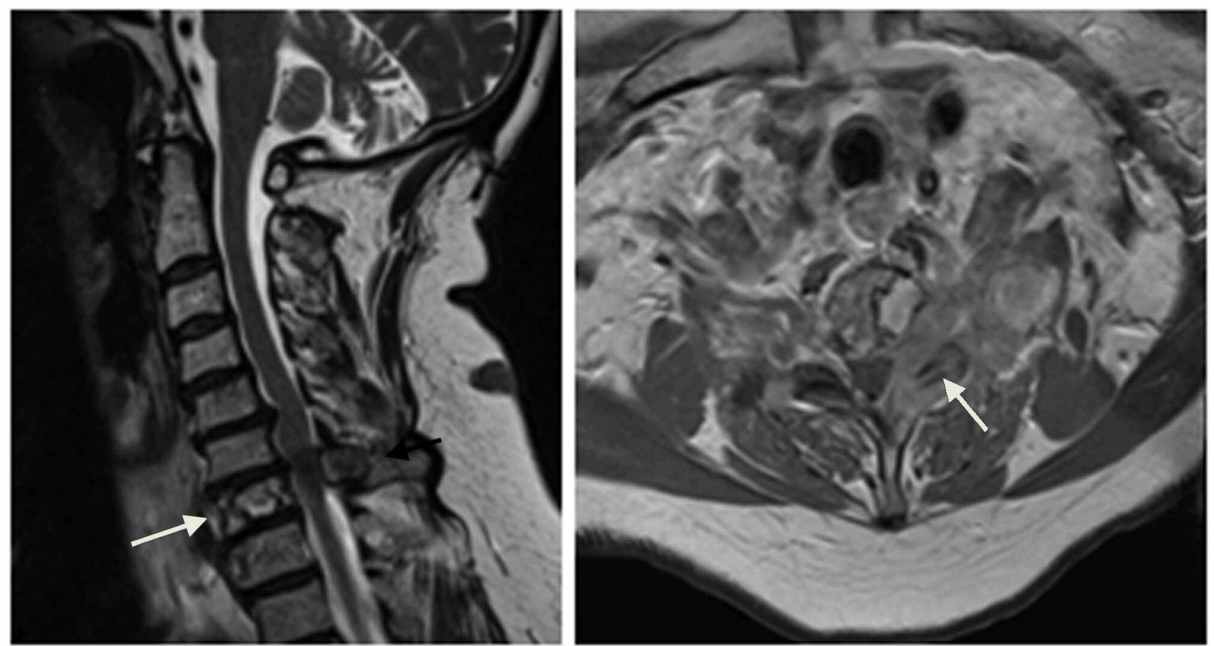

FIGURE 1: Left: Sagittal T2-weighted image of the cervical spine showing soft tissue mass invading $\mathrm{C} 7$ vertebral body and spinous process (arrow). Right: Axial post-contrast T1 weighted image of the cervical spine showing tumor extension into $\mathrm{C67}$ neural foramen (arrow).

Needle biopsy of the lesion (Figure 2) was consistent with skin adnexal neoplasm in the spectrum of cylindroma/spiradenoma.

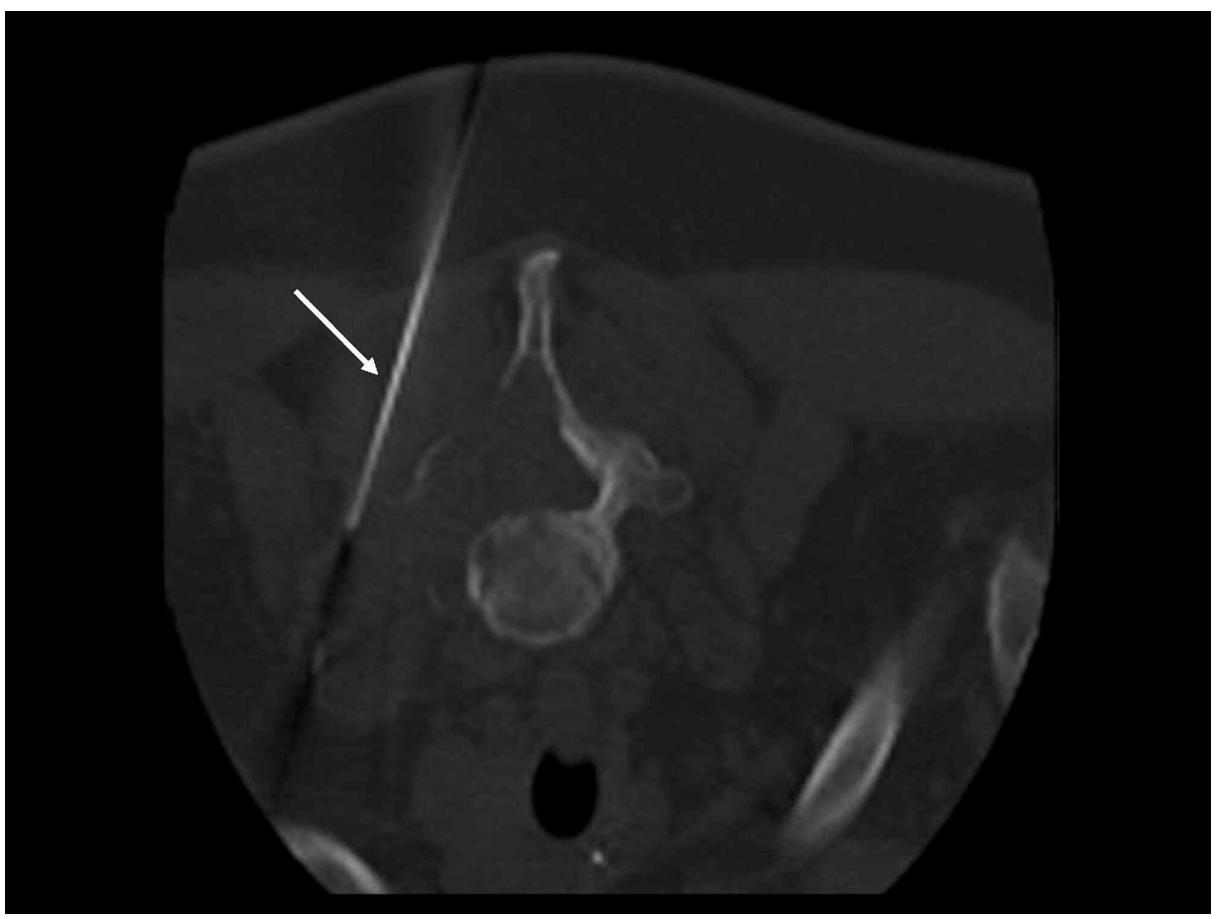

FIGURE 2: Needle biopsy tract (arrow).

Though no malignant features were detected on histologic examination (Figure 3), the unusual location of the lesion and local invasion of neural structures raised concern for malignant transformation of existing cylindromas. No genetic analysis was done. The patient was subsequently lost to follow up. 


\section{Cureus}

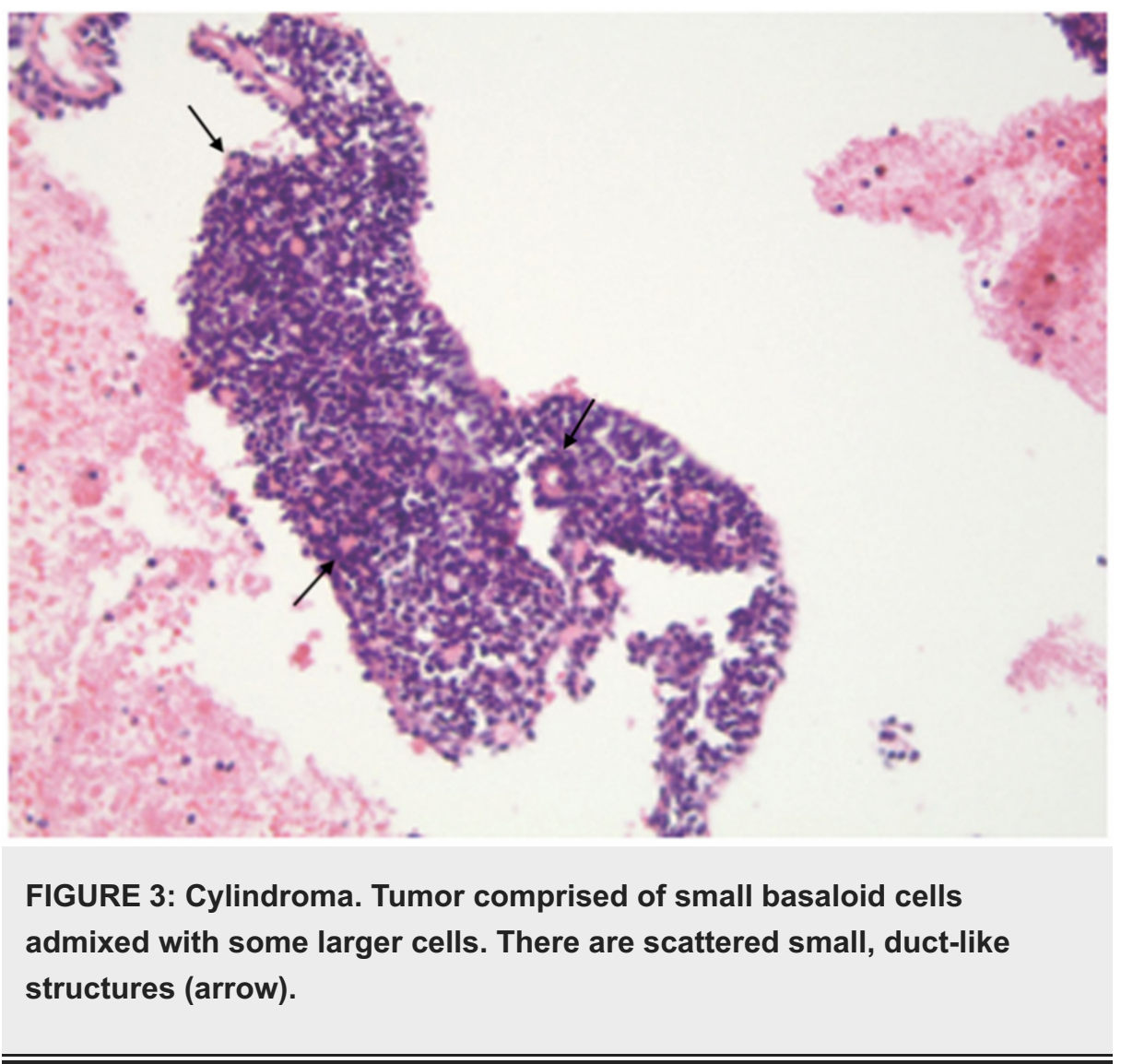

\section{Discussion}

Malignant cylindroma (cylindrocarcinoma) is an extremely rare entity with distant metastatic spread being an exceptional event. The age of the patients with cylindrocarcinoma ranges from 50 to 96 years old; females affected more often [7]. Some of the authors report on greater preponderance for malignant transformation in the context of Brooke-Spiegler syndrome and its phenotypic variant, familial cylindromatosis [8]. The malignant tumors are usually distinguished from the benign lesions by rapid growth, ulceration, bleeding, and pain [9]. Seventy-two cases of malignant cylindromas have been described in the literature. There are less than 20 cases of lymph node and distant metastatic spread of malignant cylindromas [10]. The malignant tumor most likely spreads along draining lymphatic vessels to the associated regions [11]. The regions of distant metastasis include cervical and visceral lymph nodes, lung, and pleura [10,12]. Direct invasion of the cranial bone and intracranial compartment has also been observed with malignant cylindromas of the scalp [11,13]. Benign cylindroma eroding through the skull vault has only been reported once [14].

In summary, this case demonstrates a unique behavior of histologically benign cylindroma with new site of metastatic occurrence and local invasion. This is the first case reported in the literature of this pattern of behavior.

\section{Conclusions}

To our knowledge, this is the first case of metastatic spread of the benign cylindroma to the cervical spine resulting in local bone destruction and compromised neural elements. Physicians taking care of patient populations with Brooke-Spiegler syndrome should be aware of this rare possibility.

\section{Additional Information \\ Disclosures}

Human subjects: Consent was obtained by all participants in this study. Conflicts of interest: In compliance with the ICMJE uniform disclosure form, all authors declare the following: Payment/services info: All authors have declared that no financial support was received from any organization for the submitted work. Financial relationships: All authors have declared that they have no financial relationships at present or within the previous three years with any organizations that might have an interest in the submitted work. Other relationships: All authors have declared that there are no other relationships or activities that could appear to have influenced the submitted work. 


\section{Acknowledgements}

The authors thank Hannah Moulthrop, MS and Vimal Patel, PhD, for assistance in copy editing the manuscript.

\section{References}

1. Kim C, Kovich OI, Dosik J: Brooke-Spiegler syndrome. Dermatol Online J. 2007, 13:10.

2. Mohiuddin W, Laun J, Cruse W: Brooke-Spiegler syndrome. Eplasty. 2018, 18:ic14.

3. Trufant J, Robinson M, Patel R: Brooke-Spiegler syndrome. Dermatol Online J. 2012, 18:16.

4. Kazakov DV: Brooke-Spiegler syndrome and phenotypic variants: an update. Head Neck Pathol. 2016, 10:125-130. 10.1007/s12105-016-0705-X

5. Dubois A, Rajan N: CYLD cutaneous syndrome. GeneReviews ${ }^{\circledR}$ [Internet]. Adam MP, Ardinger HH, Pagon RA, et al. (ed): University of Washington, Seattle; 2020. http://www.ncbi.nlm.nih.gov/books/NBK555820/:

6. Kazakov DV, Zelger B, Rutten A, et al.: Morphologic diversity of malignant neoplasms arising in preexisting spiradenoma, cylindroma and spiradenocylindroma based on the study of 24 cases, sporadic or occurring in the setting of Brooke-Spiegler syndrome. Am J Surg Pathol. 2009, 33:705-719. 10.1097/PAS.0b013e3181966762

7. Durani BK, Kurzen H, Jaeckel A, Kuner N, Naeher H, Hartschuh W: Malignant transformation of multiple dermal cylindromas. Br J Dermatol. 2001, 145:653-656. 10.1046/j.1365-2133.2001.04460.x

8. Borik L, Heller P, Kazlouskaya V: Malignant cylindroma in a patient with Brooke-Spiegler syndrome . Dermatol Pract Concept. 2015, 5:9.

9. Gerretsen AL, van der Putte SC, Deenstra W, van Vloten WA: Cutaneous cylindroma with malignant transformation. Cancer. 1993, 72:1618-1623. 10.1002/1097-0142(19930901)72:5<1618::aidcncr2820720521>3.0.co;2-5

10. Akgul GG, Yenidogan E, Dinc S, Pak I, Colakoglu MK, Gulcelik MA: Malignant cylindroma of the scalp with multiple cervical lymph node metastasis - a case report. Int J Surg Case Rep. 2013, 4:589-592. 10.1016/j.ijscr.2013.02.027

11. Hammond DC, Grant KF, Simpson WD: Malignant degeneration of cranial cylindroma . Ann Plast Surg. 1990, 24:176-178. 10.1097/00000637-199002000-00013

12. Brown SM, Arefi M, Stones R, et al.: Inherited pulmonary cylindromas: extending the phenotype of CYLD mutation carriers. Br J Dermatol. 2018, 179:662-668. 10.1111/bjd.16573

13. Urbanski SJ, From L, Abramowicz A, Joaquin A, Luk SC: Metamorphosis of dermal cylindroma: possible relation to malignant transformation: case report of cutaneous cylindroma with direct intracranial invasion. J Am Acad Dermatol. 1985, 12:188-195. 10.1016/s0190-9622(85)80015-3

14. Wyld L, Bullen S, Browning FS: Transcranial erosion of a benign dermal cylindroma . Ann Plast Surg. 1996, 36:194-196. 10.1097/00000637-199602000-00017 